\title{
ADAPTATION TO CLIMATE CHANGE THROUGH THEORIES OF URBAN DEVELOPMENT
}

\author{
Dragana BLAGOJEVIĆc ${ }^{\mathrm{a}, \mathrm{b}}$, Imre NAGY ${ }^{\mathrm{b}}$, Aco LUKIĆ ${ }^{\mathrm{b}, \mathrm{c}}$, Dajana TEŠIĆ ${ }^{\mathrm{b}}$
}

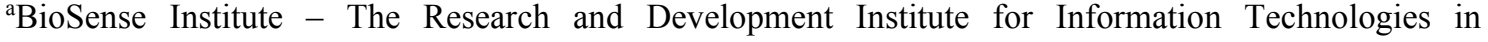
Biosystems, Novi Sad, Serbia; dragana.blagojevic@biosense.rs

bUniversity of Novi Sad, Faculty of Sciences, Department of Geography, Tourism and Hotel Management, Novi Sad, Serbia; nagyi@rkk.hu; dajanatesic2@gmail.com

${ }^{c}$ Charles University, Faculty of Science, Department of Demography and Geodemography, Prague, Czech Republic; acolukic994@gmail.com
\end{abstract}

Cite this article: Blagojević, D., Nagy, I., Lukić, A., \& Tešić, D. (2020). Adaptation to climate changes through theories of urban development. Deturope. 12(3): 37-57.

\begin{abstract}
The average temperature of the world over the past 100 years has risen by $0.6^{\circ} \mathrm{C}$. The rising temperature will likely present a big challenge for society and the environment in the future. The population has the ability to respond to it in a variety of ways, especially nowadays when technology is evolving daily. In order to reduce the harmful impacts of climate change and allow communities to thrive in the face of it, adaptation strategies are needed. These strategies need to be accepted by local and national governments, households, and industry. This paper has aimed to derive information about each and discuss the best solution. A theory of smart cities, eco-city theory, city logistics, and sustainable cities are the main strategies whose concepts have upgraded urban planning and building design that can prevent climatic damage but are still consistent with the environment. Innovative cities in developed and developing countries have demonstrated that with the appropriate strategies resource efficiency can be economically enhanced while simultaneously reducing pollution and waste. It is shown that this way improves the quality of life and supports the development of a culture of sustainability.
\end{abstract}

Keywords: climate change, adaptation, smart city, sustainability, eco-city, city logistics

\section{INTRODUCTION}

Global warming is affecting all the world today and the effect is not a good one. It is estimated that the global average surface temperature has increased by approximately $0.07^{\circ} \mathrm{C}$ per decade during the period 1901-2010 (NOAA National Centers for Environmental Information, 2019; Barry et al., 2018; IPCC, 2001). According to one of the most reliable sources, The World Meteorological Organization which coordinates weather services around the globe, the average global temperature, today compared with the second half of the 19th century, has increased by $0.85^{\circ} \mathrm{C}$ (Desyatkin, 2018) (Figure 1). It was announced that the warmest year remains 1998, while each of the last 10 years (1995-2004), apart from 1996, is one of the warmest 10 years on record (Pittock, 2005). 
Figure 1 World population and mean global temperature from 1880 to 2019

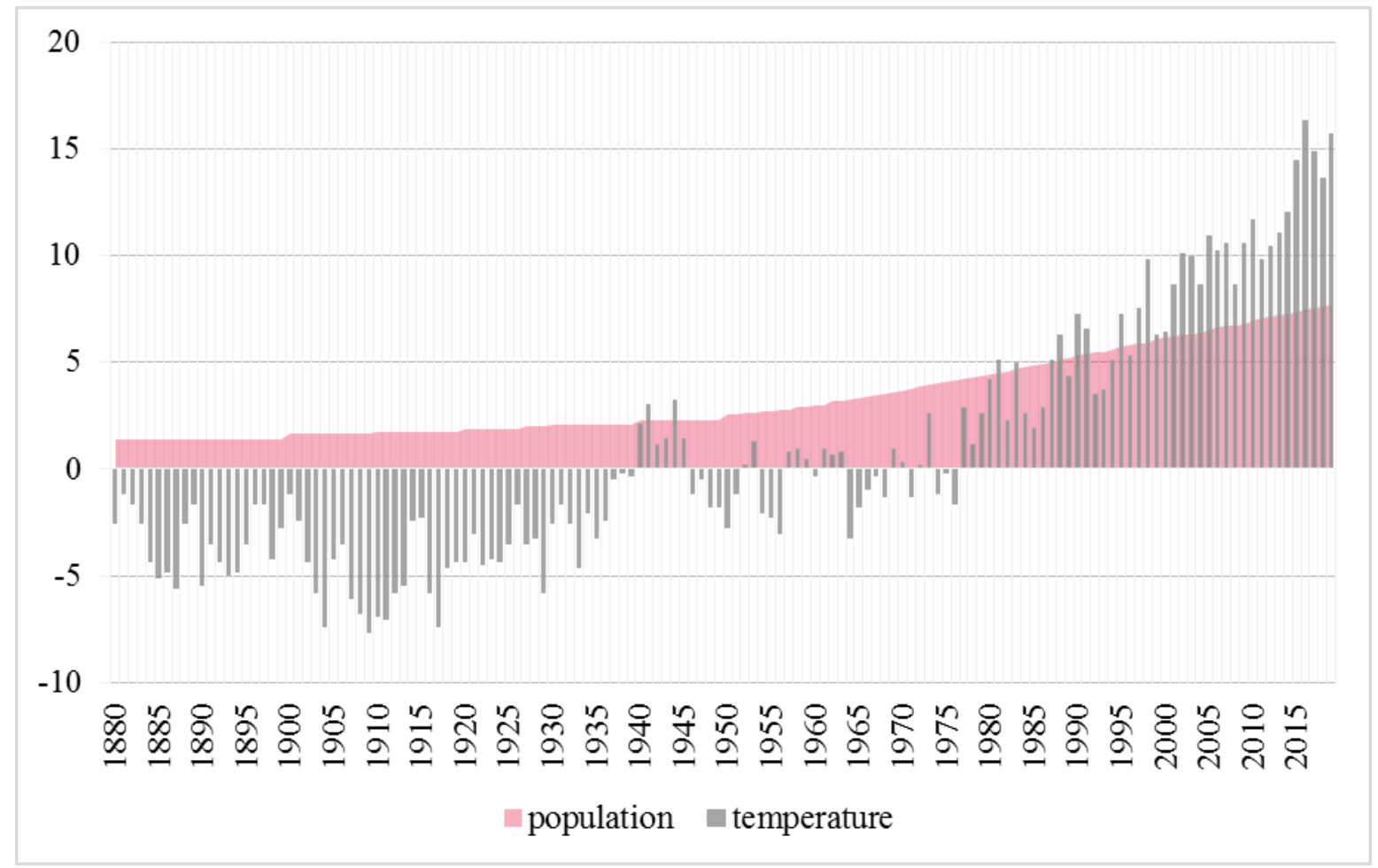

Source: https://www.temperaturerecord.org/ and https://www.worldometers.info/worldpopulation/world-population-by-year/

Its cause can be attributed to various activities. During the past century, human activities have discharged large amounts of carbon dioxide and other greenhouse gases into the atmosphere. Most of the gases come from burning fossil fuels to producing energy and deforestation as well as through waste gases from industry, farm animals, and land cultivation. If we turn back to the past, we can conclude that there are many natural causes of past climate change as well. This evidence includes continental drift, variations in the Earth's orbit around the Sun, changes in solar output, volcanic emissions, cosmic collisions, and particulate matter in the atmosphere, commonly referred to as 'aerosols (Pittock, 2005). However, while greenhouse gases build up, the climate is changing, and the results are seen in events dangerous to human health and ecosystems.

Nowadays, about half of the human population is affected by the burden of urban environments: environmental pollution, noise, the stress of the speed up lifestyle, and the modified parameters of the urban atmosphere compared to the natural environment (Unger et al., 2014). In order to face difficulties with sustainable development, including issues related to environmental health and economic stability cities should plan strategies as a part of adaptation. In the future, we will experience destructive effects on air quality and public health as well as water availability and the spread of diseases related to poor sanitation. 
Extreme weather events will cause widespread damage to infrastructure, loss of life, and livelihoods. Because of all this, urban centers are key in strategies to reduce greenhouse gas emissions, especially in reducing dependence on carbon-based fuels. Impacts of climate change vary according to geographic locations. Inland cities in the desert and subtropical locations are likely to experience longer and more serious droughts. On the other hand, in the mountainous and arctic regions, there will be less snow cover as well as shorter winters. Possibly the most serious impacts will be in coastal areas and small islands where the main risks will be rising sea levels and more frequent floods, droughts, and cyclones (Handmer et al., 2012).

The design of cities creates unique microclimates that affect variables including temperature and wind. The urban heat island effect is an example where cities are warmer than their surroundings due to the complex topography and mass of buildings, which replaced previous vegetated surfaces (Hebbert, Jankovic, \& Webb, 2011). Because of this, appropriate urban planning and building design are important. Suitable architecture can prevent buildings from warming up and ensures comfortable indoor environments. In order to reach the maximum thermal comfort in urban areas, climatic aspects should be considered at all scales, from the design of individual buildings to regional planning (Unger et al., 2014). For reasons such as these, cities often suffer from weather and climate hazards.

\section{THEORETICAL BACKGROUND}

Greenhouse gases include carbon dioxide, methane, and oxides of nitrogen, that can absorb heat radiation from the Sun and the Earth. Moreover, these gases can emit absorbed heat energy as infrared radiation in all directions. These gases are called greenhouse gases and act like a thick blanket surrounding the Earth. Natural greenhouse gases include carbon dioxide, methane, and water vapor. These help to keep Earth some $33^{\circ} \mathrm{C}$ warmer than if there were no greenhouse gases and clouds in the atmosphere (Pittock, 2005). The increase in carbon dioxide has been caused primarily by burning fossil fuels (coal, oil, and natural gas) and the clearing of forests that held reservoirs of carbon in wood and soils and removed carbon dioxide from the atmosphere through photosynthesis. The increase in the other two major greenhouse gases is mostly due to agricultural activities: methane $\left(\mathrm{CH}_{4}\right)$ through growing rice and raising cattle, and nitrous oxide $\left(\mathrm{N}_{2} \mathrm{O}\right)$ from the application of the high-temperature combustion of fossil fuels (The Maryland Commission on Climate Change, 2008). Major natural sources whose natural cycles increased the atmospheric concentration of $\mathrm{CO}_{2}$ to the 
atmosphere are animal respiration, microbial breakdown of dead organic matter and soil carbon, and ocean to atmosphere exchange (Hardy, 2003). Since inter-annual growth of $\mathrm{CH}_{4}$ slowed and became significantly variable in the 1990s, compared with the 1980s, it has been suggested that a significant ratio of the current $\mathrm{CH}_{4}$ emissions are anthropogenic rather than natural (Benson, 2008).

The effects of climate change include variations in biosphere ambient temperature, which could lead to heat stress, change in rainfall patterns, sea-level rise, saltwater intrusion, loss of biodiversity, drought, habitat loss, and freshwater depletion and pollution as well as urban infrastructure damages: electricity, water pollution, increased spread of diseases, sanitation systems, etc. (Benson, 2008; Bulkeley et al., 2009). Since more than 50\% of the world population is concentrated in cities, the human population is affected by the burden of urban environments: environmental pollution, noise, the stress of the speed up lifestyle, and the modified parameters of the urban atmosphere compared to the natural environment (Unger et al., 2014). In order to face difficulties with sustainable development, including issues related to environmental health and economic stability cities should plan strategies as a part of adaptation. Because of all this, urban centers are key in strategies to reduce greenhouse gas emissions, especially in reducing dependence on carbon-based fuels. Climate change impacts are different in different geographic locations. Inland cities in the desert and subtropical locations are likely to experience longer and more serious droughts, while in mountainous and arctic regions there will be less snow cover as well as shorter winters. Possibly the most serious impacts will be in coastal areas and small islands where the main risks will be rising sea levels and more frequent floods, droughts, and cyclones.

As a reasonable approach in dealing with this problem, there is spatial planning. Developing an urban environment in a way that ensures a safe place to live on the one hand and a clean, healthy environment on the other hand is the key to reducing emissions and adapting to possible events. The government and local authorities should encourage certain planning patterns that will contribute to the reduction of emissions and promote renewable energy sources (Bulkeley et al., 2009). This can be achieved by considering a range of solutions to city adaptation such as eco-cities, sustainable cities, smart cities, city logistics, and so on. This paper will explore these concepts with some examples and discuss the best urban development decision.

The design of cities creates unique microclimates that affect variables including temperature and wind. The urban heat island effect is an example where cities are warmer than their surroundings due to the complex topography and mass of buildings, which replaced 
previous vegetated surfaces (Hebbert et al., 2011). Because of this, appropriate urban planning and building design are important. Suitable architecture can prevent buildings from warming up and ensures comfortable indoor environments. To reach the maximum thermal comfort in urban areas, climatic aspects should be considered at all scales, from the design of individual buildings to regional planning (Unger et al., 2014). For reasons such as these, cities often suffer from weather and climate hazards.

It is important to mention that forms of adaptation are not uniform due to their dependence on geographical location. However, a specific urban form in one location might not be suitable for the other location and vice versa. Therefore it is essential to develop a form that will conform more to local or regional than global conditions (Yiannakou \& Salata, 2017).

The Intergovernmental Panel on Climate Change (IPCC) defined mitigation as any action designed to either reduce future emissions of greenhouse gases or to enhance the existing capacity of carbon sinks. In the beginning, the primary scientific focus was on mitigating greenhouse gas emissions. The main policy outlines of mitigation strategies have been closely connected to energy policy, with a tendency to increase the share of renewable sources of power, adopting efficiency goals to power and heating needs, restructuring freight and passenger transport systems to lower the greenhouse emissions. Mitigation should be considered as a form of future adaptation, with efforts to reduce current and future emissions of greenhouse gases, because it is believed that climate changes will be so great as to overwhelm the adaptive capacity of social and natural systems (Driscoll, 2010).

\section{Mitigation}

Cities have a major role in mitigation since urban residents are not just victims of climate change, but they are part of the problem, therefore they must also contribute to its solution. The best idea is to start making efforts in emissions control locally to improve the quality of life and the productivity of cities on a global level. Those efforts are invested today in cities in sectors such as construction and urban planning because they can 'lock-in' a level of emissions for the time. To avoid the dangerous impacts of climate change, it is important to do something to reduce global emissions of greenhouse gases. To do so, mitigation needs time to take effect due to the complexity of the climate system and the time necessary to reduce emissions sufficiently to stabilize climate.

Pittock (2005) in his book "Climate Change: Turning Up the Heat" defined several general ways of how mitigation can be achieved. One such solution is by increasing energy efficiency by reducing carbon dioxide emissions that were closely related to the gross domestic product 
(GDP) of individual countries during the early period of the twentieth century. Fuel substitution is another possible solution. It can be defined as the substitution of one readily available fuel with another, as distinct from the development of new alternative fuels or energy sources. Switching from coal to oil or gas can reduce greenhouse gas emissions. The main problem lies in substitution. For example, China and India are richly endowed with coal but poorly endowed with oil and gas. Other countries, such as the United States, Japan, Australia, and western European countries can afford fuel substitution. However, some 70\% of gas reserves are in the former Soviet Union and the Middle East. Limited availability of reserves of natural gas and costs may limit switching to gas supplies for power generation.

The presence of natural assets (urban parks, forests, green belts) and components (trees, water) in urban contexts contributes to the quality of life in many ways. They provide environmental services such as air and water purification, wind and noise filtering, and microclimatic stabilization (Chiesura, 2004). Cities with varied land areas as distinct urban land use, however, often comprise a mosaic of warm and cold areas as distinct urban land-use changes, for example, the change between the park and built-up area can produce intra urban temperature differences up to $7^{\circ} \mathrm{C}$. The urban landscape influences the wind pattern and regional wind speed is usually reduced by the city. Trees and buildings usually reduce the effect of the wind but may also create local areas with higher wind speeds and eddy circulations. All of this indicates how much climate in the city is dependent on factors such as land use, building geometry, and building materials. Thus, there are many reasons for urban planners to design whilst bearing climate in mind (Eliasson, 2000).

Natural hazards and their associated risks continued to occur and seemed to increase in complexity, magnitude, and frequency, causing issues in the social-economic-environmental support systems of countries affected. The Intergovernmental Panel on Climate Change (IPCC) predicts that due to climate change, the South Asia region will be affected by heavy precipitation. Many islands are vulnerable to cyclones, storm surges, tsunamis, and sea-level rise. It is very difficult to design the best approach to disaster risk reduction when the region is hit by multiple devastating disasters. Governments across the world start thinking about investing in proactive approaches with preparedness and mitigation towards disaster risk reduction. Furthermore, the collaboration and cooperation among different stakeholders, including UN agencies, regional and international organizations, civil sectors, private sectors, media, and academics are crucial for effective disaster risk reduction to improve the resilience of communities (Tyagi et al., 2016). 
The main questions this paper attempts to answer are: (1) What needs to be done to consider these urban development theories as possible solutions for climate change in cities? (2) Which strategy/theory represents the best solution? (3) What are the main challenges that these theories are facing?

\section{METHODOLOGY}

The applied research methodology consisted of the interpretation and understanding of the general effects of climate change in cities. The most recent literature on this subject was examined and discussed with a focus on different ways of adaptation and mitigation. The main method of the research was qualitative analysis through scientific papers and reports reviews. This paper aimed to underline the benefits, profits, and usefulness of investigating smart technologies in cities helping them to adapt to climate change and prepare for emergent situations. This research attempts to uncover trends in ideas and opinions, and dive deeper into the problems of urban development.

Firstly, the definition, causes, and effects of climate change needed to be discussed. This is followed by a brief review of temperature changes of the past and the challenges that big cities are facing. There are various strategies of city adaptation, but the success of their implementation depends on the government, urban policies, and citizens as well as a country's level of development. Secondly, different theories of adaptation were examined and introduced including their definitions, benefits, concepts, and application difficulties. Each city adaptation theory is explained in more detail through direct utilization examples. In the end, the action of mitigation is considered. Mitigation is an important part of a city's adaptation to climate change because it can turn theory into practice. The analysis of theories and different scientific opinions on this subject is an input for further researches since it provides a complete overview of current global issues.

\section{RESULTS AND DISCUSSION}

According to the United Nations Human Settlements Programme (UN Habitat, 2009), local government institutions responsible for urban and regional planning and development can play a proactive and coordinating role in enhancing urban food security and city resilience. Innovative cities in both the developed and developing world have demonstrated that with the appropriate strategies they can economically enhance their resource efficiency while 
Blagojević, D., Nagy, I., Lukić, A., Dajana Tešić, D.

simultaneously reducing harmful pollution and unnecessary waste. This way they have improved the quality of life of their citizens, strengthened their fiscal capacity and created an enduring culture of sustainability (Suzuki, Dastur, Moffatt, Yabuki, \& Maruyama, 2010).

There are three major types of theories of adaptation: sustainable eco-cities, smart cities, and city logistics. There are no clear, universally accepted definitions of these terms. They are interconnected and cannot be implemented individually.

\section{Sustainable cities}

There are many definitions of sustainable development. The definition proposed by Stoddart (2011) is a reliable one: the overall goal of sustainable development is the long-term stability of the economy and environment, which is only achievable through the integration and acknowledgment of economic, environmental, and social concerns throughout the decisionmaking process.

There is a considerable amount of research that defines and characterizes the form of a sustainable city. The physical dimensions include its size, shape, land uses, configuration, a city's transportation system, and urban design features (Jenks \& Jones, 2009). The environmental (water and energy saving, waste recycling, transportation, etc.) as well as social and economic criteria are central to each different definition of a sustainable city. The most important factors that can make the city livable, pleasant, and attractive for citizens are a great amount of public green spaces, public parks, and recreation areas (Chiesura, 2004). To create a sustainable urban environment, it is crucial to identify areas of opportunity as well as concern and to respond by developing realistic sustainability goals with a long-term perspective. Efficient governance informed by science-driven policies is a critical component of sustainable development (Science for Environment Policy, 2018). Egger (2006) claims that the city is not an isolated system. It impacts the sustainability of systems hosted within it, as well those within which it exists, such as regional and global ecosystems and economies. To develop cities sustainably, we need to understand the complex interactions between the environment, economy, and society.

One of the main obstacles to achieving this goal is climate change. A big challenge lies in our ability to achieve the ecological, economical, and social objectives that define sustainable cities. Building a qualitative environment is encouraging sustainable development and adaptive capacity of the city at the same time. Reducing vulnerability to the hazards associated with current and future climate variability and extremes through specific policies, 
and programs, individual initiatives, participatory planning processes, and other community approaches can reduce vulnerability to climate change.

\section{Eco-cities}

The term 'eco-city' refers to a human settlement that provides a qualitative standard of living without depleting the ecosystem, natural resources, and biogeochemical cycles on which it depends and relies ("Shenzhen Declaration on Eco-city Development 2002"; White, 2002; Witting, 2007).

The terms 'eco-city' and 'sustainable city' emerged at different points of time but now both are firmly embedded in the urban environmental sustainability agenda, more recently in the context of climate change. In practice, the term 'eco-city' is often used to describe new cities rather than the modification of existing cities (as in the case of 'sustainable cities'). The greatest challenge for these developing ideas is their public acceptance since these concepts produce radical changes in people's established views, lifestyles, and behavioural patterns (Koh, Gunawansa, \& Bhullar, 2010).

Green infrastructure can provide multiple services for the local economy. These include pollinating crops on behalf of the agri-food systems, or recharging aquifers on behalf of the water supply system, or channelling wind toward open hilltops, or creating water basins on behalf of the local energy utility. They can reduce the average temperature in cities, absorb carbon dioxide, and release oxygen, they can generally increase physical and mental wellbeing (Suzuki et al., 2010).

It is very important to ensure that the construction of eco-cities and the development of cities produces economic and social benefits, eco-efficiency, and restores the true harmony between man and nature. Urban green spaces are multifunctional in the urban context that benefits people's quality of life. In order to meet the social and psychological needs of citizens, green spaces need to be distributed throughout the city area, and the total area covered by green space in the city should be large enough to accommodate the city population's needs (Mersal, 2017). City plan developments need to include energy-efficient buildings, renewable energy, efficient distribution of clean water and waste, green transport schemes, clean air zones. These plans are not only about the construction of infrastructure for roads, buses, and railways; they are also about pricing and management, regulations applying to the location of homes, the use of cars, and the complete design of cities. All of these involve decisions of individuals on where to live, how to move, how to interact, and how to commute, and their effects on others. No plan fits all cities, each of them should pick a 
Blagojević, D., Nagy, I., Lukić, A., Dajana Tešić, D.

strategy that is the best for improving their efficiency, making greater use of renewable sources, and improving the environment for innovation (Rode et al., 2013).

One of the biggest problems that all cities are facing is the cost of green technology since it requires high initial investments. Therefore, it is very important to attract investments. In general, different investors and enterprises are invited by local authorities (central, provincial, or municipal governments) to participate in the construction and development of eco-city projects. Here, the biggest problem is when some major projects fall into the hands of private companies that turn them into an opportunity for profit. Therefore the eco-city project represents an expression of green capitalism (Saiu, 2017).

Overall, cities have a major role in protecting their citizens and economy. City government adaptation actions should contribute to identifying climate change risks, taking actions and initiatives to reduce the impacts of climate change, providing information and regulations to be more resilient to climate change. Calculating the project costs and benefits of a specific adaptation activity is a key aspect of the city planning process prior to seeking financing options.

\section{Smart cities}

The International Data Corporation - IDC defines smart city development as the use of smart initiatives combined to boost technology investments in an entire city, with common platforms increasing efficiency, data being shared across systems, and IT investments. The mission of a truly smart city is to improve the quality of life for citizens and visitors (Yesner \& Ozdemir, 2017).

Researchers say that a city is "smart" when it can integrate and synchronize formal leadership and endogenous democratic participation in the IT-based urban ecosystem. Smart cities are creative and intelligent. Strategic choice, visions, and paths differ from city to city. These planning steps are defined by the identity and resources of cities. Smart cities should offer a balanced mix of technologies, institutions, and people. They must be based on the smart combination of the contribution and activities of citizens with an awareness of the ecosystem, and the importance of high quality of life. Griffinger et al. (2007) defines five sectors of a smart city: smart people, smart governance, smart mobility, smart environment, and smart living.

Research on smart cities has also been propelled by the ever-increasing availability of data related to the urban environment. Dealing with the life cycle of city data requires de-noising, cleaning, anonymization, and privacy protection. All of this implies a need for advances and 
optimizations in software engineering and service-oriented architectures, together with the processing of distributed, networked, dynamic city-data. Obtained and analyzed data should bring tangible services and solutions to citizens. The smart city represents the future challenge, a city model where the technology serves the individual and his or her economic and social life quality improvement (Celino \& Kotoulas, 2013). Collecting spatial information in one city can be achieved by using the Internet of Things technology. This means that various types of sensors are set at different locations and are used for generating information and creating a database that needs to be analyzed. The coordination and best use of data provides the main connection between information technologies and smart city concepts. IoT helps the government and businesses in making strategic plans as well as making the best use of decision-making processes (Samih, 2019). IoT has a wide usage and application in different domains such as home automation, healthcare, education, emergency, traffic, garbage collection, etc. This way huge amounts of data are made transparent and available to citizens who will be more familiar with the state of their city and involved in managing their living environment. In addition, the data that is gathered can be analyzed, estimated, and divided in real-time and finally turned into exploitable knowledge. To accomplish something like this, information needs to be shared and visible and multiple sectors need to cooperate and work for the community and the city (Zanella, Bui, Castellani, Vangelista, \& Zorzi, 2014; Jin, Gubbi, Marusic, \& Palaniswami, 2014). Zanella et al. (2014) reported a table of services that should exist in a smart city and are connected with IoT: structural health, waste management, air quality monitoring, noise monitoring, traffic congestion, city energy consumption, smart parking, smart lighting, and automation and salubrity of public buildings. They emphasized that an urban IoT infrastructure depends on the consolidation of different kinds of technologies with already installed communication technologies. This is important due to the development of the IoT in a city that wants to be smart.

In fact, both the public and private sectors have a common goal in developing this idea. In the term of 'smart cities' Internet plays a fundamental role in communication, information sharing, and processing, data transfer, and analysis. Various operations need to be covered: business, citizens, optimizing energy and water production or consumption, traffic management, public safety, and emergency response. All of these are proof that the Internetbased solutions can successfully address societal challenges. Therefore, smart cities are dependent on country, government, natural resources, IT knowledge, and capacities as well as their ability to create a smart citizen who will be engaged and empowered and positively contribute to the city and the community. 
Blagojević, D., Nagy, I., Lukić, A., Dajana Tešić, D.

\section{City Logistics}

The idea of city logistics holds one of the keys to achieving a balance between the benefits of moving freight in, out of, and within the city and the environmental, social, and economical nuisance and cost associated with these activities (Benjelloun, Crainic, \& Bigras, 2008).

Savelsbergh and Van Woensel (2016) consider that city logistics is finding efficient ways to transport goods in urban areas while taking into account the negative effects on congestion, safety, and the environment. One of the main characteristics of city logistics is to recognize that transporting goods in urban areas has a negative (as well as a positive) impact on the lives of people living in these urban areas.

According to the Institute of City Logistics, city logistics is "the process for totally optimizing the logistics and transport activities by private companies in urban areas while considering the traffic environment, the traffic congestion, and energy consumption within the framework of a market economy." (Neto, Galves, Junior, \& Tacla, 2008, pp. 139). It concerns the means to achieve freight distribution in urban areas, by improving the efficiency of urban transportation, reducing traffic congestion, and mitigating environmental impacts (Neto et al., 2008).

It is important to emphasize that transportation infrastructure is vulnerable to flooding and higher temperatures associated with climatic changes. It will be necessary for the coming decades for spatial planners to systematically analyze the vulnerability of each portion of the transportation system and attempt to build resiliency. One of the most intractable problems in many cities is the increasing distance between residences and workplaces that are far larger than many public transport systems were built to service. As a result, many people resort to car usage to make daily trips to work, school, retail excursions, or leisure activities (Driscoll, 2010). This can be the main purpose of the city logistics concept of development, to solve problems such as these in order to protect the environment, health and to prevent drastic global climate change. There are many benefits to this idea such as: improved productivity, efficiency, customer service, traffic situation, reduced number of transport movements, reduced air pollution and noise emission, as well as higher land productivity (Benjelloun et al., 2010; Neto et al., 2008).

To develop a qualitative transport network, stakeholders must take into account users' decisions and actions and address their needs. A possible solution is to work from home as well as car-sharing and cycling. These measures can have a positive impact on traffic problems and also on people's health and lifestyles (Rezende Amaral, Šemanjski, Gautama, \& 
Aghezzaf, 2018). It is well-known that the most important characteristic of human activities is mobility. Humans are used to being on the move, to change many locations a day enabling them to have a qualitative social, healthy life. The studies showed that people who use the "ecological" way of transport are more productive at work and have better performance and more energy during the day. Active mobility has many positive effects on the lifestyle and overall health of the population as well as a great impact on the economy and working elan. This can be achieved by many strategies that involve investments in pedestrian and cycling infrastructures, better public transport connections, and taking care of their safety (UNECE, 2020).

When planning urban transport cover areas and network lines, stakeholders must be referred to the urban distribution. This information is essential for achieving the goal to successfully ensure a stable and constant connection between consumers and suppliers as well as companies and their workers. They need to follow people's movements, to try to predict their needs and predetermine the infrastructure accordingly. There are many variations in mobility. However, it depends on the purpose, intensity, routine, as well as on the part of the day. All this knowledge is part of the process of totally optimizing urban logistics activities by considering the social, environmental, economic, financial, energy, and lifestyle factors (European Platform on Sustainable Urban Mobility Plans, 2019).

The aim of this concept is to support the sustainable development of cities and to address challenging problems such as high levels of traffic congestion, negative environmental impacts, high energy consumption, and a shortage of trained labor.

\section{The model}

The model (Figure 2) represents each of these adaptation theories as well as their main advantages. There are problems that society is facing during climate change, hence possible solutions through mitigation should be considered. Each of these problems can be solved by using one of these urban development theories or a combination of more. To achieve this, key-people need to recognize it as an essential tool that they need to investigate. Key-people represent stakeholders: local community, government, citizens, households, industry, anyone who is involved in making strategies related to climate change. 
Figure 2 The model that represents a connection between ways of adaptation, problemsolving, and mitigation

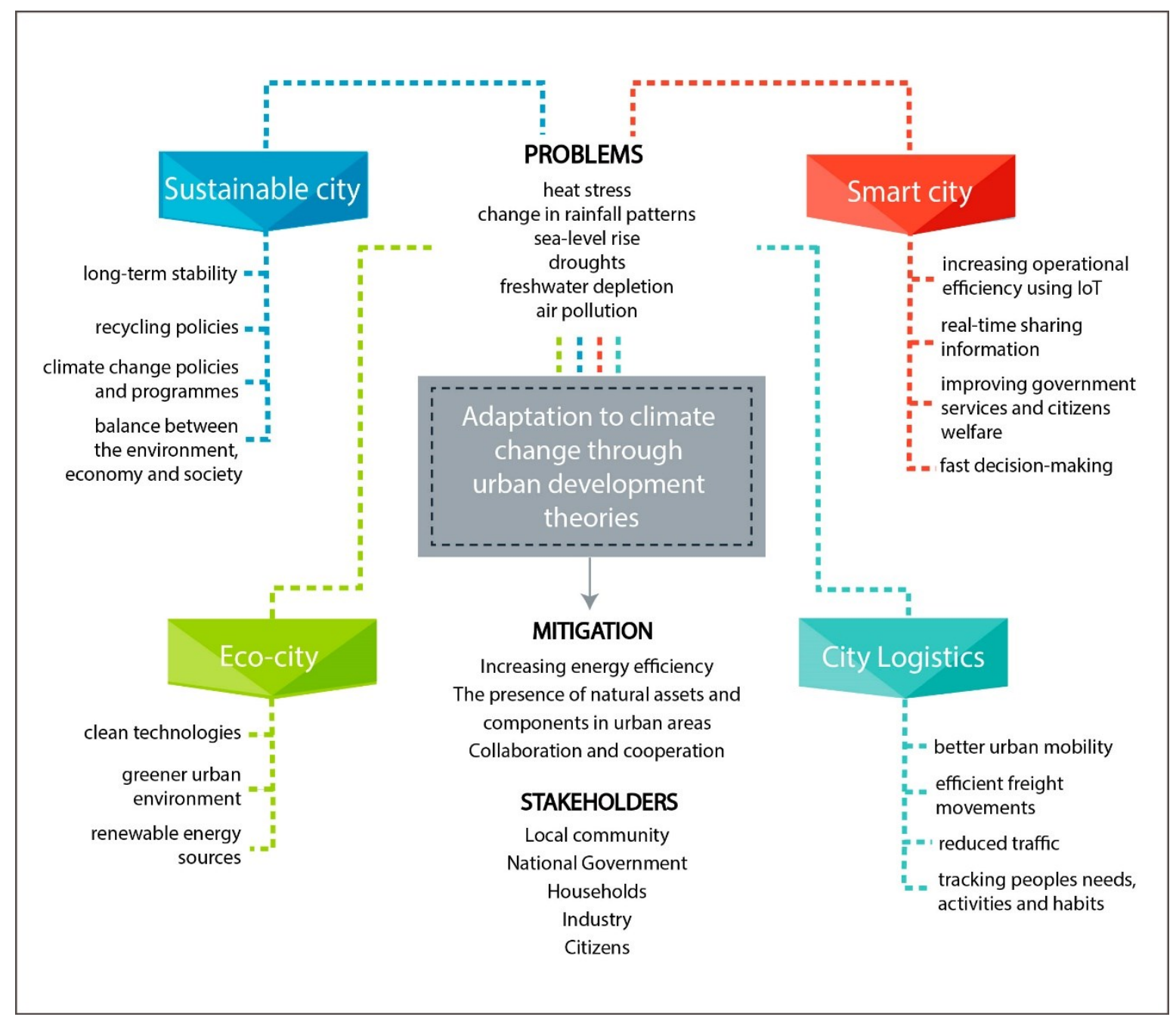

Source: Authors' construction

These urban development theories have the same goals: environmental protection, lowcarbon projects, energy efficiency, reducing pollution, economic growth, making the best out of the city. What connects them is technology, those developments need innovation in technology and successful application of it in order to promote the ecological economy. This leads us to the conclusion that not only energy, resources, transport should be in the focus but also social development and serving citizens by creating the best living and natural environment (Ji, Li, \& Jones, 2017).

However, each of the theory is dealing with and holds the solutions for different types of problems, as shown in Figure 2. The information about social urban activities can have a great impact on the development of service-based economies. Local knowledge is important for formulating the response to climate change. This response is based on the city level and the analysis of significant information about the vulnerability, potential consequences, priorities, 
Blagojević, D., Nagy, I., Lukić, A., Dajana Tešić, D.

and predictions (Heinrichs, Krellenberg, \& Fragkias, 2013). The integration of different concepts and strategies can be the last vision of these theories of urban development. In combination, a city can be digital, with green infrastructure, sustainable, and resilient. Urban sustainability is a concept that gathers all theories and is focused on economic development, population growth, climate change, and social security, and qualitative life. To deliver these, sustainability stakeholders must advocate and deliver them to the citizens who, on the other hand, need to be engaged in this process (Martin, Evans, \& Karvonen, 2018; De Jong, Joss, Schraven, Zhan, \& Weijnen, 2015).

\section{Implementations of adaptation theories}

Europe plays a leading role in international climate and environmental politics. European research is developing a great number of projects that consider urban planning strategies and designing sustainable neighborhoods. The first projects have been constructed mainly in northern Europe. The most popular examples include those of Ecolonia (Alphen Aan den Rijn, The Netherlands, 1989-1993), Vauban (Freiburg, Germany, 1997-2008), EVALanxmeer (Culemborg, The Netherlands, 1994-2009), Solar City (Linz, Austria, 1998-2001) and BedZed (London, UK, 2000-2002) (Saiu, 2017). In 1992 the United Nations presented Agenda 21, an action plan that had sustainable development goals on national and international levels. This strategy established a new global partnership. Chapter 9 Protection of the atmosphere discusses climate change, environmental protection, air pollution, the vulnerability of nature, and human impact (United Nations, 1992). More projects from Europe are the Sustainable Energy Action Plan (SEAP) and Sustainable Energy and Climate Action Plan (SECAP) in the signatory of the Covenant of Mayors. These plans aim to reduce greenhouse gas emissions between 2020 and 2030 as well as to adapt to the climate change impacts (Covenant of Mayors \& Joint Research Centre of the European Commission, 2014; 2016). The objective of the EU "to reduce GHG emissions to 80-90\% below 1990 levels by 2050" is represented through the Energy roadmap 2050 (2011). Its goal is to realise development by working as a group. The roadmap focuses on the share of energy use and contains five so-called "decarbonization scenarios" (European Commission, 2011).

China, which the Global Carbon Project identifies as the biggest carbon polluter in the world, is the single largest developer of renewable power and heat over the past eight years and has the greatest number of employees in the renewable energy sector in the world. Dongtan, Caofeidian, and Tianjin (SSTEC) are the most well-known sustainable projects in China, which can be allocated to three different approaches to the project. The first 
sustainable city developed in India is Lavasa, and Masdar is the World's first zero-carbon, a zero-waste city in Abu Dhabi. These last two projects are representative of a more technological approach, getting closer to the theoretical model of smart cities (Saiu, 2017).

The city-state of Singapore uses sensors and IoT-enabled cameras to monitor the cleanliness of public spaces, crowd density, and the movement of locally registered vehicles. Its smart technology helps companies and residents monitor energy use, waste production, and water use in real-time. In Dubai, the United Arab Emirates, smart city technology is used for traffic routing, parking, infrastructure planning, and transportation. Barcelona, Spain, uses a sensor to monitor temperature, pollution, and noise, as well as monitor humidity and rain levels (Rouse, 2017).

However, the Better World Solutions website analyzed the key objectives of the top 10 eco-cities that were ranked highest in terms of environmental sustainability. The eco-city number one is Reykjavik, Iceland. This city uses geothermal energy and almost $95 \%$ of heating is provided through this renewable source. It focuses on the development of the public transportation system and the preservation of green spaces. Upcoming cities are Zurich (Switzerland), Bristol (South West England), Portland (Oregon), San Francisco (California), etc. From 2005 to 2010 Bristol was able to reduce domestic energy use by $16 \%$. The target of this city is to reduce $\mathrm{CO}_{2}$ emissions by $40 \%$ by 2020 and by $80 \%$ by 2050 ("Top 10 EcoCities", 2019).

\section{CONCLUSION}

To avoid the worst consequences of global climate change, the global population needs to reduce present active construction and development of urban capacity and to turn their plans to the greener side of urban design. How we perform that construction and development will depend on how we accept the growing presence of information technology in all aspects of our lives (Harrison \& Donnnelly, 2011).

There are many strategies for city adaptation, as mentioned above. To be considered as possible solutions for climate change and its negative impact on cities globally, these adaptation theories need to be accepted by local and national governments, households, and industry and they need to act together. This is also the main argument while answering the first research question. When speaking about climate change adaptation in cities, it must be emphasized that it also refers to making existing and new infrastructure resistant to the effects of climate change. Since these strategies are focused on certain actions in terms of 
transportation, energy, food and agriculture, urban greening, and green infrastructure, one has to apply a smart approach in considering which of them, or maybe a combination of these, will contribute the most to better urban living, better functioning of industry, and protection of the environment.

Additionally, while adopting the eco-city theory, it is essential to determine its sustainability since the environmental sustainability of eco-cities is questionable. Eco-cities employ several ecological ideas and clean technologies to test their potential to reduce the ecological footprint, but on the other side, they pay less attention to the environmental impact during the planning and construction stage. Finally, the development and maintenance of ecocities will require a reconceptualization of current legal and policy frameworks (Koh et al., 2010).

A theory of smart cities is developed on the intense interest in the role of information technology in cities. It is time to develop a solid theoretical foundation and to develop an understanding of how these technical methods can help to achieve today's goals and challenges (Harrison \& Donnnelly, 2011). It can be concluded that a smart city is a municipality that uses information and communication technologies to increase operational efficiency, share information with the public, and improve both the quality of government services and citizen welfare. Sustainable and eco-city are often considered as the same term because of the absence of a universally acceptable definition. The city logistics enables the mobility of urban freight through the transportation of goods by or for commercial entities taking place in an urban area. This strategy is centered on ensuring efficient freight movements and innovative responses to the urban customer and business demands. Based on these descriptions and definitions of these theories, the answer to the second research question is that they are not independent. When making a decision on which one to implement, confusion can easily occur. There is no "one-best" solution because each theory produces results in different areas, but they work for the same goal and that goal is adaptation to climate change through specific urban development. Because of this fact, the best strategy is a multidisciplinary approach to problem solving.

All theories are facing many challenges when it comes to their implementation or adoption by responsible institutions. The main challenge for city logistics is global urbanization, the level of concentration of the global population living in cities is increasing (Rácz, 2019). On the other hand, this population can contribute to the realization of better city connection, availability of certain industries, better functionality of society and mobility. It depends on the strategy to meet these challenges by fulfilling the requirements, aims, regulations, and 
policies. The greatest challenges for smart city and eco-city theories are high costs of the required technology and business logistics as well as its inaccessibility to the wider population. To make society, industry and city sustainable, strategies need to take into account their habits, mentalities, activities, and understand what they consider sustainable because after all a city must be customized for people.

To summarize, the rising concentration of carbon dioxide in the atmosphere is a consequence of the burning of fossil fuels for various economic activities. The other causes of climate change include agriculture and changes in land-use patterns. To reduce the harmful impacts of climate change and allow communities to thrive in the face of climate change, adaptation strategies are needed. It is obvious that some adaptation measures do impact the urban landscape and the development of green areas changes people's perception of the city. Because of this, before making a decision about which strategy is the best it is essential to consider patterns in human behavior in terms of energy use, and their dwelling or office in general so that energy consumption in the city can be modified. The second main task is mitigation. Mitigation strategies should offer feasible and cost-effective ways to reduce greenhouse gas emissions. these include the use of clean and renewable energy for electricity production as well as developing greener urban infrastructure.

\section{REFERENCES}

Barry, A. A., Caesar, J., Klein Tank, A. M. G., Aguilar, E., McSweeney, C., Cyrille, A. M., ... \& Touray, L. M. (2018). West Africa climate extremes and climate change indices. International Journal of Climatology, 38, 921-938. DOI: 10.1002/joc.5420

Benjelloun, A., \& Crainic, T. G. (2008). Trends, challenges, and perspectives in city logistics. Proceedings of Transportation and land use interaction, TRANSLU, 8, 269284.

Benson, N. (2008). Climate Change, Effects. In S. G. Philander (Ed.), Encyclopedia of Global Warming and Climate Change (pp. 210-214). USA: Sage Publications, Inc. DOI: $10.4135 / 9781412963893 . n 129$

Bulkeley, H., Schroeder, H., Janda, K., Zhao, J., Armstrong, A., Chu, S. Y., \& Ghosh, S. (2009). Cities and Climate Change: The Role of Institutions, Governance and Urban Planning_in Cities and Climate Change: Responding to an Urgent Agenda, Hemdon, VA, USA: World Bank, 125-159.

Celino, I., \& Kotoulas, S. (2013). Smart Cities [Guest editors' introduction]. IEEE Internet Computing, 17(6), 8-11. DOI: 10.1109/MIC.2013.117

Chiesura, A. (2004). The Role of Urban Parks for the Sustainable City. Landscape and Urban Planning, 68(1), 129-138. DOI: 10.1016/j.landurbplan.2003.08.003

Covenant of Mayors \& Joint Research Centre of the European Commission (2014). Reporting Guidelines on Sustainable Energy Action Plan and Monitoring. Retrieved from: 
http://dev.eumayors.eu/IMG/pdf/Reporting_Guidelines_SEAP_and_Monitoring_v2-02.pdf

Covenant of Mayors \& Joint Research Centre of the European Commission (2016). The Covenant of Mayors for Climate and Energy Reporting Guidelines. DOI: $10.2790 / 586693$

De Jong, M., Joss, S., Schraven, D., Zhan, C., \& Weijnen, M. (2015). Sustainable-smartresilient-low carbon-eco-knowledge cities; making sense of a multitude of concepts promoting sustainable urbanization. Journal of Cleaner Production, 109, 25-38. DOI: 10.1016/j.jclepro.2015.02.004

Desyatkin, R. V. (2018). Climate change and the dynamics of permafrost ecosystems of continental cryolithozone of the northern hemisphere. Vestnik RAS, 88(12), 494-501. DOI: $10.31857 / \mathrm{S} 086958730003190-7$

Driscoll, P. A. (2010). Climate Change Mitigation, Adaptation and Sustainable Urban Development: A Case Study of Copenhagen and Portland. Urban Planning and Management (Report No. 3). Aalborg University.

Egger, S. (2006). Determining a sustainable city model. Environmental Modelling \& Software, 21(9), 1235-1246. DOI: 10.1016/j.envsoft.2005.04.012

Eliasson, I. (2000). The use of climate knowledge in urban planning. Landscape and Urban Planning, 48(1), 31-44. DOI: 10.1016/S0169-2046(00)00034-7

European Commission (2011). Energy roadmap 2050. Retrieved from: https://ec.europa.eu/energy/sites/ener/files/documents/2012_energy_roadmap_2050_en - $0 . p d f$

European Platform on Sustainable Urban Mobility Plans (2019). Sustainable Urban logistics Planning. Retrieved from:

https://www.eltis.org/sites/default/files/sustainable_urban_logistics_planning.pdf

Giffinger, R., Fertner, C., Kramar, H., Kalasek, R., Pichler-Milanovic, N., \& Meijers, E. (2007). Smart cities - Ranking of European medium-sized cities (Report). Vienna University of Technology, Austria.

Handmer, J., Honda, Y., Kundzewicz, Z. W., Arnell, N., Benito, G., Hatfield, J., Mohamed, I. F., Peduzzi, P., Wu, S., Sherstyukov, B., Takahashi, K., \& Yan, Z. (2012). Changes in impacts of climate extremes: human systems and ecosystems. In Field, C. B. et al. (Eds.), Managing the Risks of Extreme Events and Disasters to Advance Climate Change Adaptation: A Special Report of Working Groups I and II of the Intergovernmental Panel on Climate Change (IPCC) (pp. 231-290). Cambridge University Press, Cambridge, UK, and New York, NY, USA.

Hardy, J. T. (2003). Climate change: causes, effects, and solutions. United States: John Wiley $\&$ Sons.

Harrison, C., \& Donnelly, I. A. (2011). A theory of smart cities. Proceedings of the 55th Annual Meeting of the ISSS-2011, 55(1), Hull, UK.

Hebbert, M., Jankovic, V., \& Webb, B. (Eds.) (2011). City weathers: Meteorology and urban design, 1950-2010. Manchester, England: Manchester Architecture Research Centre.

Heinrichs, D., Krellenberg, K., \& Fragkias, M. (2013). Urban Responses to Climate Change: Theories and Governance Practise in Cities of the Global South. International journal of Urban and Regional Research, 37(6), 1865-1878. DOI: 10.1111/1468-2427.12031

IPCC, 2001: Climate Change 2001: The Scientific Basis. Houghton, J. T., Ding, Y., Griggs, D. J., Noguer, M., Van der Linden, P. J., \& Xiaosu, D. (Eds.), Intergovernmental Panel on Climate Change. Cambridge University Press, Cambridge, UK. www.ipcc.ch

Jenks, M., \& Jones, C. (Eds.). (2009). Dimensions of the sustainable city (Vol. 2). Berlin, Germany: Springer Science \& Business Media. 
Ji, Q., Li, C., \& Jones, P. (2017). New green theories of urban development in China. Sustainable Cities and Society 30, 248-253. DOI: 10.1016/j.scs.2017.02.002

Jin, J., Gubbi, J., Marusic, M., \& Palaniswami, M. (2014). An Information Framework for Creating a Smart City Through Internet of Things. IEEE Internet of Things Journal 1(2), 112-121. DOI: 10.1109/JIOT.2013.2296516

Koh, K. L., Gunawansa, A., \& Bhullar, L. (2010). "Eco-Cities" and "Sustainable Cities" Whither? Social Space, 84-92.

Mersal, A. (2017). Eco City Challenge and Opportunities in Transferring a City into Green City. Procedia Environmental Sciences, 37, 22-33. DOI: 10.1016/j.proenv.2017.03.010

Maddox, T. (2018, July 2016). Smart cities: A cheat sheet. TechRepublic. Retrieved from https://www.techrepublic.com/article/smart-cities-the-smart-persons-guide/

Martin, C., Evans, J., \& Karvonen, A. (2018). Smart and sustainable? Five tensions in the visions and practices of the smart-sustainable city in Europe and North America. Technological Forecasting and Social Change, 133, 269-278. DOI: 10.1016/j.techfore.2018.01.005

Neto, A. P., Galves, M. L., Júnior, O. L., \& Tacla, D. (2008). Challenges of urban transport problems and city logistics: Sao Paulo city center case. WIT Transactions on The Built Environment, 101, 133-142. DOI: 10.2495/UT080131

NOAA National Centers for Environmental Information, State of the Climate: Global Climate Report for Annual 2019 (2020). Retrieved from

https://www.ncdc.noaa.gov/sotc/global/201913.

Pittock, B. A. (2005). Turning up the heat. London, United Kingdom: Earthscan.

Rácz, S. (2019). Development Processes of Regional Centres in Central and Southeast Europe - From State Socialism to Dependent Market Economies. Deturope, 11(2), 92100. http://www.deturope.eu/img/upload/content92-100.pdf

Rode, P., Floater, G., Kandt, J., Baker, K., Montero, M., Heeckt, C., Smith, D. \& Delfs, M. (2013). Going Green: How Cities Are Leading the Next Economy. LSE Cities

Rezende Amaral, R., Šemanjski, I., Gautama, S., \& Aghezzaf, E-H. (2018). Urban Mobility and City Logistics - Trends and Case Study. Promet 30(5), 613-622. DOI: $10.7307 /$ ptt.v30i5.2825

Rouse, M. (2017). New Trend in IoT: Digital Twin Tech. IoT Agenda. Retrieved from https://internetofthingsagenda.techtarget.com/definition/smart-city

Saiu, V. (2017). The Three Pitfalls of Sustainable City: A Conceptual Framework for Evaluating the Theory-Practice Gap. Sustainability, 9(12), 2311. DOI: $10.3390 /$ su9122311

Samih, H. (2019). Smart cities and internet of things. Journal of Information Technology Case and Application Research, 21(1), 3-12. DOI: 10.1080/15228053.2019.1587572

Savelsbergh, M., \& Van Woensel, T. (2016). 50th anniversary invited article-city logistics: Challenges and opportunities. Transportation Science, 50(2), 579-590. DOI: $10.1287 /$ trsc. 2016.0675

Shenzhen Declaration on Eco-city Development (2002). The Fifth International Eco-City Conference. Adopted by the attendees of the fifth international eco-city conference, Shenzhen, China.

Stoddart, H. (Ed.) (2011). A Pocket guide to sustainable development governance. London, UK: Stakeholder Forum.

Suzuki, H., Dastur, A., Moffatt, S., Yabuki, N., \& Maruyama, H. (2010). Eco2cities: ecological cities as economic cities. Washington, DC: World Bank.

The Maryland Commission on Climate Change (2008). Comprehensive Assessment of Climate Change Impacts in Maryland. University of Maryland Center for Environmental Science, Cambridge, Maryland. 
Top 10 Eco Cities (2020, February 9). Retrieved from https://www.betterworldsolutions.eu/top-10-eco-cities/

Tyagi, B., Saluja, S., Srivastava, N., Bharti, N., Bhattacharya, P. K., Aslam, S., \& Aggarwal V. (2016). Effects of Various Disaster Management Approaches: An Evidence Summary. Contextualisation of Review Findings for South Asia and Bangladesh. London: EPPI-Centre, Social Science Research Unit, UCL Institute of Education, University College London.

UNECE (2020). A Handbook on Sustainable Urban Mobility and Spatial Planning. Geneva. Retrieved from: http:/www.unece.org/fileadmin/DAM/trans/main/wp5/publications/ 1922152E_WEB_light.pdf

United Nations Human Settlements Programme (UN-Habitat) (2009). Planning Sustainable Cities - Global Report on Human Settlements, Earthscan, UK and USA.

United Nations (1992). Agenda 21. United Nations Conference on Environmental \& Development, 3-14 June Rio de Janeiro, Brazil. Retrieved from:

https://sustainabledevelopment.un.org/content/documents/Agenda21.pdf

Unger, J., Savić, S., Gál, T., Milošević, D., Kosztolányi, É., \& Marković, V. (2014). Urban climate and monitoring network system in Central European cities. Novi Sad, Serbia: University of Novi Sad, Faculty of Sciences and University of Szeged, Department of Climatology and Landscape Ecology.

Yesner, R., \& Ozdemir, F. (2017). Understanding Smart City Transformation with Best Practices. International Data Corporation, Istanbul, Turkey.

Yiannakou, A., \& Salata, K. D. (2017). Adaptation to Climate Change through Spatial Planning in Compact Urban Areas: A Case Study in the City of Thessaloniki, Sustainability 9(2), 1-18. DOI: 10.3390/su9020271

White, R., R. (2002). Building the Ecological City. Cambridge, United Kingdom: Woodhead Publishing Ltd.

Wittig, R. (2007). Principles for Guiding Eco-City Development. In Carreiro, M. M. et al. (Eds.) Ecology, Planning, and Management of Urban Forests: International Perspectives (pp. 29-34). New York: Springer.

Zanella, A., Bui, N., Castellani, A., Vangelista, L., \& Zorzi, M. (2014). Internet of Things for Smart Cities. IEEE Internet of Things Journal, 1(1), 22-32. DOI: 10.1109/JIOT.2014.2306328 